\title{
ESTRATÉGIAS DE MARKETING: UM ESTUDO DE CASO DA EMPRESA CIA DA TERRA, EM FORMOSA-GOIÁS
}

\section{ARTIGO ORIGINAL}

GUIMARÃES JUNIOR, José Carlos ${ }^{1}$

GUIMARÃES JUNIOR, José Carlos. Estratégias de Marketing: Um estudo de caso da Empresa CIA da Terra, em Formosa-Goiás. Revista Científica Multidisciplinar Núcleo do Conhecimento. Ano 05, Ed. 11, Vol. 15, pp. 44-58. Novembro de 2020. ISSN: 2448-0959, Link de acesso:https://www.nucleodoconhecimento.com.br/administracao/estrategias-demarketing

\section{RESUMO}

Esse artigo é resultado de uma pesquisa realizada na empresa Cia da Terra LTDA, localizada em Formosa-Goiás. O objetivo da pesquisa foi de abordar temas diretamente relacionados ao comportamento organizacional e as estratégias que eles usam para buscar a satisfação dos clientes, justamente por entenderem que a melhor proposta de marketing é a satisfação do cliente, pois assim conseguirá não só a fidelização, mas também a adesão de novos clientes. Para que a pesquisa fosse coberta de êxito, várias teorias foram estudadas, através dos seus conceitos e aplicabilidades, que fazem parte da construção do referencial teórico, que definem o direcionamento do trabalho, baseado em vários autores sobre o tema analisado, como embasamento para as considerações do estagiário. As informações obtidas na

1 Doutorado em andamento em Biodiversidade e Biotecnologia na Amazônia. Mestrado em Planejamento e Gestão Ambiental. Especialização em Administração Rural. Aperfeiçoamento em Propriedade Intelectual. Aperfeiçoamento em Aperfeiçoamento Profissional Formação Empreendedor. Aperfeiçoamento em Windows Nt Total. Graduação em Administração de empresas. 
pesquisa serão convertidas em dados, na tentativa de se verificar a influência do modelo organizacional na satisfação do cliente

Palavras chaves: Administração, gestão, planejamento, Marketing.

\section{INTRODUÇÃO}

De acordo com Robbins (2002, p. 2) entende-se por organização "uma unidade social conscientemente coordenada, composta por duas ou mais pessoas, que funciona de maneira relativamente continua, para atingir um objetivo comum", a partir desse conceito de organização e comparando com a visão de Argyris (1975, p. 23), que define: "as organizações são sistemas extremamente complexos, que envolvem atividades humanas suscetíveis de diversos tipos de análises, e uma delas relacionase a satisfação/insatisfação nas relações entre empresa/cliente e como a satisfação do cliente pode ser considerado o melhor marketing para a empresa".

Schmenner (1999), destaca que "a organização que oferecer satisfação ao cliente terá um grande diferencial, mostrando estar apta a atender melhor as necessidades de seus clientes". A empresa que tem como prioridade o consumidor der atenção especial para as reclamações e sugestões, isto porque na maioria das vezes que um cliente é mal atendido ele não reclama, mas também não volta, inclusive podendo causar prejuízos futuros fazendo o marketing negativo da empresa.

$E$, ainda que, a qualidade no atendimento, entendendo que o atendimento é um ato como prestação de serviço, e uma ferramenta de grande valor na fidelização dos clientes, ela evidencia os esforços da empresa para manter vantagem competitiva entre a organização e seus concorrentes, pois o consumidor está mais exigente em relação à qualidade dos produtos e serviços, portanto as empresas que desejam continuar competitivas precisam ter foco no cliente e para atingir esse objetivo é preciso obter um diferencial do concorrente, ter uma equipe preparada para satisfazer as necessidades dos clientes.

As organizações procuram manter seus clientes altamente satisfeitos atingindo suas expectativas, reduzindo assim a probabilidade de que eles procurem seus 
concorrentes. As vezes pequenos detalhes como o nome do cliente, um bom dia, seja bem vindo, volte sempre ou uma ligação para saber se a mercadoria foi entregue corretamente e no prazo combinado são alguns detalhes que fazem a diferença.

Na visão de Schmenner (1999,p. 104) "A mais importante das categorias de resultados é a que mede o grau de satisfação do cliente". O processo de qualidade de um produto, depende essencialmente da boa qualidade da matéria-prima utilizada e do serviço executado no processo de fabricação. É necessário que as pessoas envolvidas nesse processo estejam adequadamente treinadas, para produzirem com mais eficiência evitando cometer erros, procurando atingir um padrão de excelência na qualidade oferecida.

Para Gil (1997, p. 23) "qualidade é, prioritariamente, eficácia no atendimento ao consumidor/cliente, na satisfação de seus anseios/desejos de consumo". A empresa deve sempre ter em vista esse procedimento como proposta de marketing.

O ponto forte de todas as empresas, na busca de novos clientes e a fidelização dos mesmos, está na sua proposta de marketing, portanto, pode-se definir como: "Marketing eficaz significa a entrega de bens e serviços que os consumidores desejam e necessitam. Significa obter produtos para eles no tempo certo, no local certo e no preço que estão dispostos a pagar" (Mccarthy, 1997, p. 29).

A imagem dos Serviços ao Cliente é representada pela somatória de bons atendimentos. Portanto, uma empresa não pode ser negligente em nenhum momento, pois, basta um atendimento confuso ou ineficaz para que venha abaixo todo o conceito de imagem da empresa construído ao longo tempo. (COBRA, 2001).

Para que a boa imagem da empresa seja sempre mantida é necessário que todos tenham um comprometimento com o bom atendimento desde o porteiro ou telefonista até o presidente da empresa, todos devem estar compromissados com o atendimento Cortês e eficaz, que todas as dúvidas, queixas e reclamações sejam sempre atendidas e resolvidas, caso contrário o nome da empresa estará comprometido. 
Um fator de suma importância para adquirir e manter os clientes fiéis à empresa é manter um atendimento diferenciado, voltado para satisfação do cliente e para que isso ocorra é preciso ter o cliente interno satisfeito, para melhor atender o cliente externo. Esse é conceito vastamente defendido por Cobra (2001), no que se refere a interação empresa/cliente.

Apesar de se ouvir que as empresas estão voltadas para o cliente, isso na maioria das vezes só ocorre na teoria, pois na pratica nem sempre é dessa forma que ocorre, pois ainda existem muitas queixas de clientes, que não são atendidas, em que as organizações não tratam de forma eficaz as reclamações recebidas.

"Em uma operação, a qualidade só é melhorada quando todos os envolvidos se conscientizam de que suas próprias tarefas podem afetar a qualidade e que talvez precisem redirecionar seus procedimentos e hábitos para a prevenção de erros." (SCHMENNER,1999, p. 104).

Para evitar problemas de qualidade são necessárias mudanças nas atitudes e hábitos de gerentes e trabalhadores, pois tal mudança de atitude é essencial para obter melhorias significativas na qualidade, procurando atingir um padrão de "zero defeito" e para que isso aconteça se espera que todos produzam com zero defeito ou que mudem o procedimento utilizado de forma a eliminar os erros de modo que tudo seja feito correto diariamente. É importante tornar a qualidade responsabilidade de todos, já que o problema em uma área da empresa pode passar para outra e se transformar em um problema, com efeitos danosos à qualidade do produto ou serviço entregue. As necessidades e desejos dos clientes devem sempre fazer parte da proposta de estratégias de atendimento e prestação e qualidade de serviços prestados aos clientes.

Figura 1- Organograma da Satisfação do Cliente 


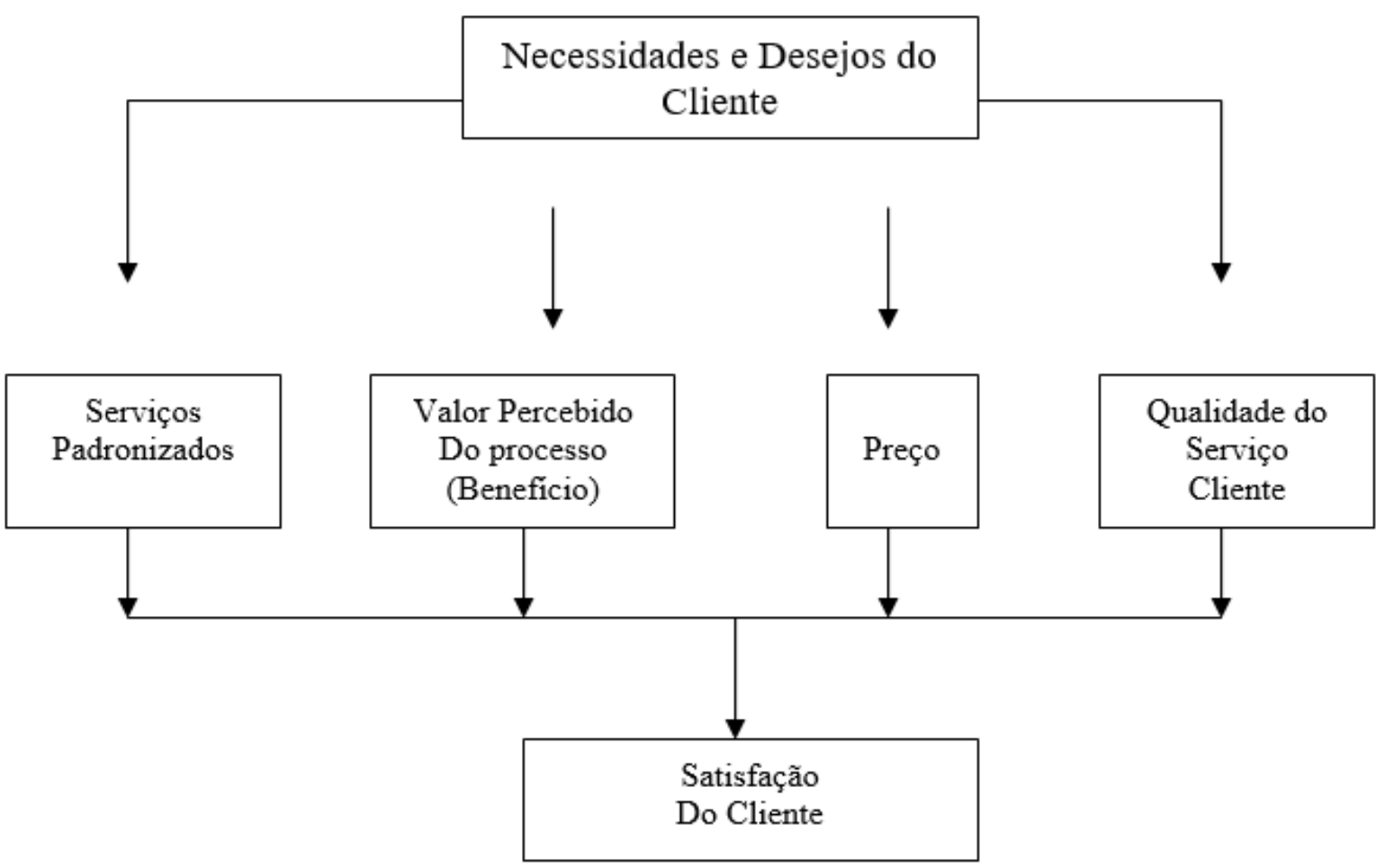

Fonte: COBRA, 2001(com adaptações)

A satisfação do cliente tem sido buscada por todas as empresas ao longo dos tempos, várias são as hipóteses levantadas, visando alcançar essa meta, entendendo que cliente satisfeito é cliente fiel.

Nesse aspecto a CIA DA TERRA tem procurado oferecer um atendimento de qualidade, entendendo que na atualidade a valorização do cliente deve ser priorizada dentro da proposta de busca à fidelização do cliente, visto que a concorrência acirrada exige das empresas qualidade na prestação de serviços, oferta de produtos e atendimento ao cliente.

\section{MARKETING DE SERVIÇOS}

Apesar da maioria das empresas saber a grande importância de oferecer alta satisfação aos clientes, muitas empresas não seguem essa filosofia, pois encontram muitos obstáculos como um alto investimento em pesquisa de mercado, tecnologia avançada para a aquisição de produtos mais sofisticados, além do treinamento de 
todos os funcionários que é primordial para manter um bom relacionamento com o consumidor, desvendando seus mais profundos desejos.

Cobra (1992), afirma que de o fato das empresas não optarem pela alta satisfação do cliente, têm dado margem ao consumidor de fazer pesquisa de mercado, e optar pela empresa que dispor de mais pontos positivos em relação ao atendimento e a prestação de serviços.

Ainda o mesmo autor, comenta que; "O serviço ao cliente é a execução de todos os meios possíveis de dar satisfação ao consumidor por algo que ele adquiriu" (COBRA, 1992, p.374).

Para atingir a satisfação dos clientes é preciso oferecer um produto que possa suprir suas necessidades e proporcionar benefícios ao consumidor, como a garantia do produto, o serviço de instalação e a certeza de obter assistência técnica quando necessário outro fato importante na obtenção da satisfação é a qualidade no atendimento.

O Sistema de Atendimento ao Cliente - SAC, tendo sido muito procurado por clientes não satisfeitos com o atendimento de empresas, no que se refere à prestação de serviços e/ou qualidade dos produtos, esse órgão destinado a sanar dúvidas dos clientes, principalmente no que se refere à relação de direitos e deveres das empresas.

Segundo Kother (1998, p.53) "a satisfação é o sentimento de prazer ou de desapontamento resultante da comparação do desempenho esperado pelo produto ou resultado em relação às expectativas da pessoa".

O nível de satisfação ao cliente tem que ser elevado para que seus desejos sejam realizados, porque atualmente os consumidores têm uma grande variedade de escolha por diversos tipos de produtos, marcas, preços e fornecedores e para que a empresa conquiste estes consumidores, suas expectativas têm que ser atingidas. 
O fator alta satisfação é importante, mas tem que haver o cuidado para que não se criem expectativas ilusórias, deixando o consumidor desapontado caso essas expectativas não sejam atingidas.

Através da excelência no atendimento se conquista a fidelidade e lealdade do cliente, o bom atendimento é essencial por que os consumidores para se tornarem fieis a empresa, precisam estar altamente satisfeito, caso contrário estará propenso a mudar, pois não terá vínculo com a organização, porque suas expectativas não foram superadas, somente foi mais viável adquirir aquele produto ou serviço pelo fator preço ou qualidade, mas quando a concorrência cobrir a oferta provavelmente irá mudar, por isso não basta o cliente estar satisfeito, mas sim plenamente satisfeito, de maneira que a possibilidade de mudança é muito menor, devido a empresa ter adquirido credibilidade e confiabilidade dos seus clientes.

De acordo com Cobra (2001, p. 19) "mais importante do que ter um produto ou serviço para ofertar, é ter um cliente para satisfazer para reter um cliente é preciso proporcionar diversas conveniências, com o objetivo de tornar esse cliente fiel. Uma vez que cliente satisfeito é cliente fiel".

É necessário manter um excelente relacionamento com os compradores da empresa, por que com tantas escolhas, as organizações enfrentam um grande índice de abandono, devido a infidelidade dos consumidores a empresa. Portanto proporcionar bem-estar, conforto, segurança ao cliente, auxilia na confiabilidade que ele depositará na empresa, através do relacionamento que lhe foi dispensado, apesar de ser dispendioso manter essa relação empresa/cliente, vale a pena por evitar a perda de clientes para os concorrentes.

No que se refere a implementação de mudanças comportamentais dentro da empresa, visando a satisfação do cliente Gil (1997, p. 52), afirma que "é preciso ter em mente que a mudança é, freqüentemente, construtiva e, por conseguinte, desejável.”, citando ainda alguns procedimentos básicos para que isso aconteça: treinamento dos profissionais em novas tecnologias e práticas empresariais; agregar novas máquinas e equipamentos às funções desempenhadas pelos profissionais da organização; 
estimular o descobrimento/criação de novos procedimentos/formas de realização/cumprimento das funções exercidas pelos trabalhadores; investir em pesquisas e desenvolvimento mantendo um canal formal para pioneirismo e evolução, via inovação tecnológica; transportar novas tecnologias do ambiente externo para o âmbito da organização e, inclusive, intercambiando tecnologia dentro da organização - transferência de tecnologia; premiação dos talentos inovadores, via programas sistemáticos de incentivos.

Uma das principais mudanças, que visam trazer a satisfação do cliente, é justamente o marketing, de acordo com Cobra (2001) "(...) a adoção do marketing é hoje um fato irrefutável.", e é nisso que as empresas têm se baseado melhorar sua performance em relação a atuação no mercado.

Atualmente, sabe-se que além de preocupar com o marketing, é preciso ir além: "o importante é saber usar com discernimento as ferramentas de que o Marketing pode dispor ordenando-as estrategicamente para ajudar a alavancar melhores resultados econômicos; financeiros e sociais." (COBRA, 1992, p. 49).

Pequenas e grandes empresas sabem que são necessárias estratégias, para se conseguir alcançar suas metas, isso pode ser comprovado em Cobra (1992, p. 104), onde destaca que estratégia de marketing, em sentido mais amplo, é um plano completo de como se faria o melhor uso de recursos para atingir uma meta.

Aspectos perceptivos de qualidade que os consumidores têm do atendimento e do atendimento recebido, relaciona-se a visão que eles têm do que pode ser percebido como estratégia de marketing da empresa sobre um ambiente e o contexto no qual está envolvido.

\section{ATENDIMENTO DE QUALIDADE COMO DIFERENCIAL NA PRESTAÇÃO DE SERVIÇOS}

Uma nova forma de marketing tem sido explorada pelas empresas, tendo em vista a busca de formas de não só satisfazer o cliente, mas também trazer a alta satisfação 
e a fidelização, essa nova proposta está relacionada a forma com que a empresa lida com a relação direta com seus clientes, para entender essa nova proposta será avaliada várias definições de CRM, ou seja a forma como as empresas podem obter alto índice de retenção de clientes e alta lucratividade: "o produto certo (ou serviço), para o cliente certo, pelo preço certo, na hora certa, pelos canais certos, para satisfazer aos desejos ou necessidades dos clientes."

De acordo com Swift (2001), a maneira como você atende a seus clientes é um importante diferenciador competitivo, já que o preço é somente um diferenciador de atração, já que, segundo o autor, muitos concorrentes podem equiparar os preços aos dos demais, ou igualá-los aos mostrados em uma publicidade.

Na maioria das vezes as empresas usam como forma de satisfação do cliente, a forma de atendimento - o relacionamento, procurando atendê-lo prontamente, profissionalmente e cortesmente, atendendo suas necessidades e dando-Ihes razões que os forcem a voltar (fidelização).

Definindo CRM, segundo Swift (2001, p. 12), "Customer Relationship Management, ou seja, a Gerência de Relacionamento com Clientes é uma abordagem empresarial destinada a entender e influenciar o comportamento dos clientes, por meio de comunicações significativas para melhorar as compras, a retenção, a lealdade e a lucratividade deles."

O redimensionamento que acontece nas metas empresariais, atualmente, baseado no CRM, deve-se ao fato de que o mesmo é um processo interativo que transforma informações sobre os clientes em relacionamentos positivos. Cabe destacar que cada empresa deve decidir o que significa CRM para a organização e para o futuro de seu sucesso no mercado.

\section{CARACTERIZAÇÃO DA ORGANIZAÇÃO E ANÁLISE AMBIENTAL DA EMPRESA}


A empresa pesquisada é denominada CIA DA TERRA, razão social J.J. Macedo Ltda, de propriedade dos sócios: Jair Neves Macedo e Helder Macedo, configurando o modelo de sociedade familiar. As atribuições são distribuídas entre os sócios, cabendo a parte financeira aa Jair Neves Macedo responsável e a Helder Macedo as decisões relacionadas à compra e venda de produtos. A empresa, fundada em 2000, situa-se à Avenida Posto Agropecuária no 66 - Centro, na cidade de Formosa-GO, é formada por dois sócios, um médico veterinário (prestador de serviços) e quatro funcionários, e suas atividades são direcionadas à venda de produtos agropecuários. A empresa não possui Planejamento Estratégico, onde perceba-se a missão, visão e valores. No mercado de atuação da cidade de Formosa, possui inúmeros concorrentes que oferecem produtos e serviços, na mesma linha de atuação na CIA DA TERRA. Os produtos de venda disponíveis pela empresa são; ração, suplementos agrícolas, produtos de pesca, sementes, selaria, medicamentos e produtos veterinários. A prestação de serviços oferecido pela empresa vai desde o serviço de entrega, até o atendimento do médico veterinário, responsável pela orientação, consulta e atendimento na loja ou em domicílio ou ainda na fazenda, em se tratando e grandes animais.

A Empresa CIA DA TERRA, possui em seu cadastro, cerca de 500 (quinhentos) clientes cadastrados, buscando, tanto a prestação de serviços, quanto a aquisição de produtos.

A distribuição das atividades e responsabilidades de pessoal fica definida da seguinte forma: o atendimento prestado pelo médico veterinário é de duas vezes na semana, por um período de 3 (três) horas diárias. O serviço de caixa é feito por funcionária que fica responsável por notas fiscais, recebimentos e pagamentos, crediário e etc.

A área de vendas emprega os serviços de 03 (três) vendedores, que estão capacitados a tirar as dúvidas dos clientes, especificar a utilidade e cuidados com cada um dos produtos disponíveis na loja, assim como emitir boletos de vendas e organizar para que as entregas sejam feitas em tempo hábil. O serviço de entrega é feito de forma precisa, evitando-se que o cliente tenha prejuízos em relação aos prazos. 


\section{ANÁLISE AMBIENTAL}

A análise ambiental é uma forma útil de ajudar as organizações a identificar sistematicamente as formas, fraquezas, oportunidades, ameaças. (MEGGINSON, 1998).

Pontos fortes: Poucas empresas que atuam nesse segmento na cidade; condições e forma de pagamento diferenciados e produtos diferenciados que atendem à demanda de diversos segmentos de consumidores.

Pontos fracos: Falta de treinamento dos vendedores no que se refere ao atendimento aos clientes e necessidade de implantação de entrega dos produtos em domicílio (a maioria na zona rural)

\section{AMEAÇAS}

Após realizar a pesquisa na empresa, objeto desse estudo, citamos abaixo, algumas variáveis que consideramos como sendo ameaças; concorrência predatória muito forte no mercado de Formosa; falta de capital de giro; mão-de-obra pouco qualificada; atraso constante no pagamento dos salários dos funcionários; ausência de um planejamento de marketing mais agressivo; falta de visão de planejamento e gestão por parte dos proprietários.

\section{OPORTUNIDADE}

Quanto às oportunidades podem ser apontadas as seguintes: Mercado crescente na cidade de Formosa e no entorno; facilidade de acesso a mão-de-obra qualificada e treinada, pois na cidade existe três Instituições de Ensino Superior que oferecem cursos na área de Administração, formando excelentes profissionais que podem ser aproveitados: Surgimento de outros fornecedores que ofertam produtos similares e com custos mais interessantes do que os já praticados no mercado; facilidade de crédito para investimento em infra-estrutura e treinamento de pessoal

\section{METODOLOGIA DA PESQUISA}


A pesquisa foi realizada em duas etapas complementares e inter-relacionadas, tendo envolvido levantamento de informações em fontes secundárias e primárias, conforme detalhado a seguir: Fez-se necessário uma revisão bibliográfica referente ao tema treinamento, qualidade no atendimento e marketing de serviços, mais especificamente referindo-se à capacitação, treinamento e capacitação de mão-de-obra.

$\mathrm{Na}$ concretização da aplicação do questionário, obteve-se como resultado, informações qualitativas, que serviram de base para sugerir medidas para mitigar alguns problemas identificados e a sugestão de novos programas de treinamento e aperfeiçoamento dos recursos humanos envolvidos em todos os processos da empresa.

No que refere ao instrumento definido para a pesquisa foi o questionário, compostos por nove perguntas fechadas.

A escolha fundamentou-se em Gil (2002, p. 114), “o questionário constituí o meio mais rápido e barato de obtenção de informações, além de não exigir treinamento de pessoal."

De acordo com o autor a elaboração de um questionário é bastante objetivo, tendo em vista que: "o questionário consiste basicamente em traduzir os objetivos da pesquisa em itens bem redigidos". Dessa forma, considera-se que o questionário seja o instrumento que atenta aos interesses da pesquisa em questão.

questionário como instrumento de pesquisa tem as seguintes vantagens e desvantagens: o questionário tem a vantagem de ser abrangente quanto ao número de itens a serem avaliados. E, apresenta como desvantagem a abordagem quantitativa das respostas em detrimento da qualitativa por falta de dados mais abrangentes para enriquecimento das respostas.

A aplicação do questionário ocorreu nas dependências da própria empresa, através da solicitação aos clientes para respondê-los, e foi determinado o período de 15 (quinze) dias consecutivos, e o intervalo foi do dia 2 a 17 de dezembro de 2019. 


\section{ANÁLISE DOS RESULTADOS OBTIDOS}

Tipo de compras: $O$ total de $80 \%$ das opções serem de varejo é significativo para caracterizar o grupo de clientes que compra por atacado é pequena, visto que somente $20 \%$ dos entrevistados fizeram essa opção. Esse resultado permite-nos concluir que como a grande maioria dos negócios da empresa são realizados quase que na sua totalidade no varejo, ou seja, existindo um contato direto entre o cliente e o vendedor, fato esse que deve ser mais bem analisado, no sentido de que os colaboradores, envolvidos no processo de oferta dos produtos ou os prestadores de serviços, devem estar muito bem preparados para estar em contato com seus clientes.

No que se refere a identificação do número de vezes que o cliente fez negócios: Identificou-se que $70 \%$ dos entrevistados já adquiriram algum tipo de produto ou contrataram algum serviço da empresa. Isso mostra que o percentual de clientes satisfeitos com o atendimento recebido na empresa, porém, um percentual importante de $30 \%$, ainda mostra que existe um caminho a percorrer, no sentido de fidelizar esses clientes, fazendo com que esses voltem a realizar algum tipo de compra na empresa.

Pergunta no 03- Grau de satisfação dos clientes: observa-se um elevado índice de satisfação dos clientes em relação à qualidade do produto e dos serviços prestados, dado que $80 \%$ consideram a qualidade entre ótima e boa e somente $20 \%$ como razoável. O índice referente a razoável (20\%) deve ser analisado mais profundamente, no sentido de se identificar quais os motivos que levam a esse percentual de clientes a ter essa opinião. Algumas variáveis devem ser pesquisadas, tais como; preço, atendimento (nesse caso deve-se identificar qual(is) os colaboradores envolvidos no processo e em que condições aconteceu a situação.

No que se refere a organização das mercadorias na loja, os resultados identificam índice de satisfação entre ótimo e bom de $80 \%$, cabe ressaltar que o percentual de $20 \%$, entre razoável e péssimo pode ser um indicativo de insatisfação, e $30 \%$ consideraram ótima a disposição das mercadorias na loja. 
Em uma análise ampla, podemos concluir que existe um grau de aceitação confortável no que se refere a disposição dos produtos. Essa variável é importantíssima na análise do conceito de marketing de serviços, embalagens, design, dentre outras variáveis que interferem no processo de aquisição de produtos ou contratação de serviços.

O alto índice $80 \%$ ( ótimo e bom), consideraram-se satisfeitos a diversidade de produtos que são oferecidos na empresa. A oferta de variedade de mercadoria esta relacionada à motivação e a necessidade, demandas, expectativas que seus clientes demandam.

O alto índice de insatisfação dos clientes, no que se refere a acessibilidade de preços, promoções e descontos pode ser comprovados pela proporção de $60 \%(44 \%+16 \%)$, entre razoável e péssimo, cabe destacar que somente $16 \%$ dos clientes estão altamente satisfeitos, optando por ótimo.

Grau de qualidade do atendimento: $O$ índice de "insatisfação" representado por $36 \%$, se somado a $24 \%$ de "razoável ", é considerado um índice alto. Observandose a importância do atendimento na relação entre a empresa e os clientes, o fato de somente $24 \%$ estarem completamente satisfeitos é indicativo de que existem problemas nesse relacionamento e deve ser mitigado de maneira urgente, através de treinamento dos colaboradores, além de estabelecer um planejamento para treinamentos mais freqüentes da mão-de-obra.

Grau de percepção do cliente em relação ao conhecimento do produto/serviços pelo vendedor: No que se refere à prestação de serviços e ao conhecimento do produto, a adequação das informações recebidas podem ser consideradas entre razoável e boa, visto que $31 \%$ dos participantes optaram por cada um desses itens, inclusive não houve predominância na escolha nem de péssimo e nem de ótimo.

Grau de percepção de solução de problemas pelos colaboradores(problemas Rreferentes aos clientes): Os resultados mostram claramente a insatisfação dos clientes no que se refere à solução dos problemas 
apresentados. Essa análise só vem corroborar com as percepções observadas nas análises anteriores, onde é possível identificar que os colaboradores não estão nem um pouco preparados para oferecer um atendimento com qualidade aos seus clientes; e, como uma conseqüência lógica, os índices de venda da empresa sofrem uma queda drástica, trazendo prejuízo presentes e futuros a organização.

\section{PROPOSTAS E SUGESTÕES}

Não obstante, sugere-se algumas medidas mitigatórias dos problemas identificados, devem ser aplicadas em caráter urgente, e seguem a seguir: Promover encontros com fornecedores e os gestores da empresa e vendedores, com o objetivo de integrar com maior efetividade o relacionamento entre os atores envolvidos nesse processo; Aprimorar o plano de cargos e salários dos vendedores, estabelecendo-se metas mais agressivas, e premiando-se os melhores resultados, seja através de uma promoção funcional, financeira, etc.; Desenvolver política de marketing mais agressiva, procurando buscar novos mercados, através da segmentação, bem como a manutenção dos clientes já existentes, procurando-se estabelecer uma relação mais forte de relacionamento entre o produto, marca e os desejos, expectativas e necessidades dos clientes; Implementar uma política de treinamento e capacitação da mão-de-obra da empresa, de maneira que não se torne uma medida tomada somente no intuito de resolver problemas de imediato, mas que torne-se uma ferramenta comum nas atividades empresariais da empresa.

\section{PROPOSTAS DE MUDANÇA NOS PROCESSOS DA EMPRESA CIA DA TERRA}

Em análise as respostas obtidas, é perceptível que algumas medidas devem ser tomadas em caráter imediato, pois estão promovendo resultados negativos nas atividades da organização.

Da mesma forma, não devemos pensar em imediatismo e, como já sugerido no item anterior, a implantação de um sistema de treinamento constante na empresa deve ser implementado em caráter também de urgência. 
Quanto aos limites para a aplicação das propostas e resultados esperados, comentamos que; a empresa Cia da Terra tem uma cultura familiar, incrustada nas mais tradicionais formas e maneiras de administração que pode-se observar, fator esse que é preocupante para aprimorar os mecanismos propostos, porém, não devemos tornar-nos desestimulados com esse fator, deve-se sim, mostrar, pensandose a médio e longo prazo, através da mostra de resultados alavancados nos processos de vendas da empresa bem como na melhoria na prestação dos serviços oferecidos pela empresa.

Uma outra variável que pode ser decisiva para a implementação das medidas sugeridas são as que se referem a "gastos" com treinamento de mão-de-obra.

Um primeiro pensamento que percebemos é " eu, gastar com esses funcionários e depois eles voltam de pedem as contas”. Essa colocação não está errada no seu todo, porém existem experiências que comprovam que, quando o funcionário retorna de um programa de treinamento, sua satisfação em prestar os serviços melhora consideravelmente, porém não devemos esquecer também que o fator remuneração deve ser revisto também, no sentido de remunera-lo mais ou ainda, ar outras responsabilidades.

\section{CONSIDERAÇÕES FINAIS}

Portanto, essa pesquisa serviu para identificar as variáveis que funcionam de maneira negativa, e que devem ser consideradas em uma análise de todo o processo de oferta, negociação e venda dos produtos, bem como da prestação dos diversos serviços que a empresa oferece.

Dessa forma, colocando-se em prática as sugestões propostas e utilizando-se as ferramentas sugeridas, torna-se pouco provável o insucesso das atividades da empresa no mercado em que atua, e, ao mesmo tempo, sugere-se que as propostas elencadas sejam encaminhadas aos gestores da empresa, dando subsídios para o aprimoramento de suas atividades e ainda sugere-se que os temas propostos por essa pesquisa sejam aprofundados. 


\section{REFERÊNCIAS BIBLIOGRÁFICAS}

BIRD, Drayton. Bom Senso em Marketing Direto/ tradução Michelangelo Di Vito. São Paulo: Makron Books do Brasil Ltda.

COBRA, Marcos. Administração de marketing. $2^{\mathrm{a}}$ ed. São Paulo: Atlas, 1992. . Marketing Básico: uma abordagem brasileira. $4^{a}$ ed. São Paulo:

Atlas, 1997

. Estratégias de marketing e serviços. $2^{\underline{a}}$ ed. São Paulo: Atlas, 2001.

GIL, Antonio de Loureiro. Gestão da qualidade empresarial. $2^{\underline{a}}$ ed. São Paulo: Atlas, 1997.

Antonio Carlos. Como elaborar um projeto de pesquisa. $4^{\underline{a}}$ ed. São Paulo: Atlas, 2002

KOTLER, Philip. Administração de marketing: análise, planejamento, implementação e controle. 5ª ed. São Paulo: Atlas, 1998.

LAKATOS, Eva Maria. Metodologia do trabalho científico: procedimentos básicos, Pesquisa Bibliográfica, Projeto e Relatório, Publicações e Trabalhos Científicos./Eva Maria Lakatos e Marina de Andrade Marconi. $6^{\underline{a}}$ ed. São Paulo: Atlas, 2001

MADRUGA, Roberto. Guia de implementação de marketing de relacionamento e CRM. São Paulo: Atlas, 2004.

SCHMENNER, Roger W. Administração de operações e serviços. São Paulo: Futura, 1999.

SENAC. Qualidade em prestação de serviços. Editora Senac Nacional, 2000. RJ

Enviado: Setembro, 2020. 
Aprovado: Novembro, 2020. 